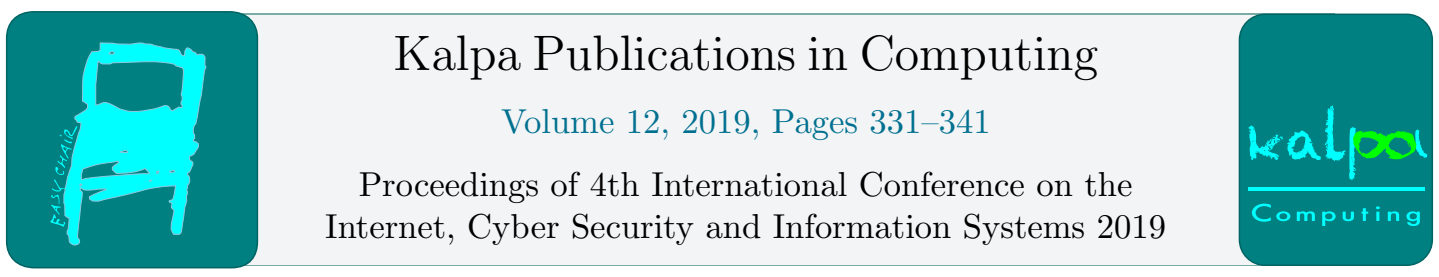

\title{
Determinants of attitudes towards social networking advertising: The role of habit, perceived ease of use and social media capital affinity
}

\author{
Babalwa Solani ${ }^{1}$ Liezel Cilliers ${ }^{2}$ and Willie Tafadzwa Chinyamurindi ${ }^{3}$ \\ ${ }^{1}$ University of Fort Hare, Department of Industrial Psychology, Alice - South Africa \\ ${ }^{2}$ University of Fort Hare, Department of Information Systems, East London - South Africa \\ ${ }^{3}$ University of Fort Hare, Department of Business Management, Alice - South Africa \\ bsolani@ufh.ac.za, lcilliers@ufh.ac.za, wchinyamurindi@ufh.ac.za
}

\begin{abstract}
There is an observed popularity in the use of social networking sites. The popularity of social networking sites appears to occupy a multi-layered utility depending on the needs of the end user. Calls exist within the literature for studies that explore understanding of determinants that influence attitudes towards advertising on social networks. The importance of this is that such factors influencing attitudes towards advertising on social networks can be useful pre-cursors to the formation of actual intentions. The objective of this study was to determine the role of habit, perceived ease of use and social media capital affinity on attitudes towards social network advertising amongst students at rural campus. A sample of 289 registered students were used as a sample for this study utilising a positivist research philosophy and a survey design approach. The findings of the research saliently show a positive relationship to exist a) perceived ease of use and habit; b) social capital affinity and attitudes towards social networking advertising. Based on the findings of the research some implications are made concerning possible responses from the youth market and attitudes towards social media advertising.
\end{abstract}

\section{Introduction}

The focus of this study was to investigate the determinants that influence attitudes towards social network advertising using a sample of students at a rural campus in South Africa. According to Thurairaj et al. (2015), the Internet has aided the advancement of social media platforms to affect individual lived experiences. Related to this, there is an observed move away from traditional 
communities to the emergence of online communities aided by social media (Lau, 2017). Social media can be then be understood as an indicator of online communities where individuals share, create, comment, and interact with online content (Anstead \& O'Loughlin, 2015). The main feature of social media and SNS is the interaction and maintenance of relationships by a collection of participants (Anstead \& O’Loughlin, 2015) resulting in more quests for social affiliation (Ma \& Chan, 2014) and greater interaction (Lau, 2017). Notably, social media has become popular especially amongst younger users (Woo \& Lee, 2017) especially amongst university students (Lin \& Wang, 2017). Calls exist within the literature for studies that explore those determinants that influence the attitudes of social media usage (van Rhyne, Chinyamurindi \& Cilliers, 2019). All this especially within the youth and student market as these are frequent users of technology (Meier, Reinecke \& Meltzer, 2016).

Narrowly, this study explores the role of habit, perceived ease of use and social media capital affinity for three reasons. First, habit has been found as an important factor that influences not just social media usage but also the ensuing attitudes (Shava \& Chinyamurindi, 2018). Second, perceived ease of use relates more with issues around the formation of intentions (Chinyamurindi \& Louw, 2010). In essence, the perceived ease of use is likely to lead to the formation of positive experiences which in turn encourage continual usage. Finally, given that social media use can be influenced by factors that are communal, social media capital affinity as argued by Ma and Chan (2014) gives focus to the sense of community and likeness people have with their online community. The identified factors (habit, perceived ease of use and social media capital affinity) relate to factors are individual, those that relate with usage and finally, those factors relating to community. In essence, this study tests how all this influences the framing of attitudes towards social media use.

\section{Theoretical Literature}

This section discusses the theoretical literature used in this study. Notably, this included: a) the theory of reasoned action and $b$ ) the theory of planned behaviour in trying to understand the constructs under-study. With regard to the theory of reasoned action (Ajzen, 1991), the theory seeks to understand how individual behaviour through the interaction of attitudes and social factors inform behaviour and the framing of subjective norms (Ajzen \& Fishbein, 1980). Further, attitudes manifest in individual behaviours provide a platform from which overall performative evaluations can be made (Hansen, Jensen \& Solgaard, 2004). Generally, individuals who have more favourable attitudes and perceive stronger subjective norms regarding a behaviour are more likely to show greater intentions to perform that behaviour. Another useful framework in explaining individual behaviour is the theory of planned behaviour (Hyde \& White, 2009). According to the theory of planned behaviour, the immediate determinants of an individuals' behaviour are their intentions. Intention is predicted therefore by three independent dimensions: attitude, subjective norm, and perceived behavioural control (Ajzen, 1991). Attitude is defined as an individual's favourable or unfavourable evaluation of performing a target behaviour. Subjective norm refers to an individual's perception that most people who are important to him or her think he/she should or should not perform the behaviour in question.

\section{Empirical Literature}

This section outlines existing empirical literature and hypotheses of the study.

Perceived ease of use refers to the extent to which a person believes that using a particular system would be free of effort (Brush et al, 2005). In essence, perceived ease of use measures a person's 
subjective assessment of efforts needed to use the system. Consistent with the technology acceptance literature (Borzillo, Aznar, \& Schmitt, 2011), the perceived ease of use of technology should lead to positive attitudes toward that technology. Positive attitudes may be engendered through the navigation of the social networking websites and the interaction with other members of the social network or application (Haythornthwaite, 2005). The primary concern of the individual is their interaction with others. The easier for an individual user to engage with others, the more positive the user should feel regarding the tool that they are using (Hensen et al., 2004).

The term social capital has multiple definitions (Adler \& Kwon, 2002). A consensus appears to be social capital as a benefit an individual receives from their social relationships (Lin, 2008). For an individual to accumulate social capital, it is important that they form and maintain relationships. Coleman (1988) perceives social capital as consisting of those resources that are accumulated by individuals by virtue of the relationships they build. In this regard, Ellison et al.'s (2007) study found a strong association to exist between the use of social networking sites usage with social capital. To further understand the issue, Steinfield, Ellison, and Lampe (2008) conducted a longitudinal analysis of panel data from Facebook users and found a strong association between intensity of social networking site use and three indicators of individuals' social capital i.e. a) perceived bridging social capital; b) perceived bonding social capital, and finally, c) perceived maintained social capital. A study by Barker, Dozier, Weiss, and Borden (2013) found that intensity of social networking use to be a strong predictor of both concentrated experience of an activity and social capital affinity. In another study, Ellison, Vitak, Gray, and Lampe (2014) found that Facebook users had higher level of bridging social capital than those users who do not use Facebook.

Perceived ease of use measures a person's subjective assessment of efforts needed to use the system (Brush et al, 2005). The ease of use also entails overcoming barriers that impede usage (Chen \& Wells, 2000). A barrier that may also be encountered concerning ease of use may include issues of a social nature (Lin, 2008). This is due to the importance of relationships as a capital that individuals rely on (Coleman, 1988). Further, when users of social media perceive their social media experience to be easy, it allows them to have a great deal comfort (Lau \& Lee, 2018). Attitudes towards advertising have been broadly researched over the past few decades and it was found that consumers' attitudes towards advertising have a direct influence on attitudes towards the brand that impacts intention-to-purchase and purchase. Additionally, attitudes towards advertising have also been deemed to be an efficient measure of advertising effectiveness (Yoo et al., 2010). The appropriateness of traditional advertising theories to online advertising has been an area of interest to academics and advertising scholars since the arrival of online advertising. Traditional methods continue to be applicable to the environment of online advertising, as the basic objectives of online advertising are inclined to be comparable to the objectives of traditional advertising, and theoretical models created for traditional advertising have effectively been transferred to online advertising (Rodgers \& Sheldon, 2000). From both an academic and marketing practitioner perspective, the hierarchy-of-effects model has received extensive attention as a detailed explanation of how advertising works, and hence is a base for measuring advertising effectiveness (Yoo et al., 2010).

Based on all the presented literature, it can be expected that:

H1: There is a relationship between perceived ease of use and habit.

$\mathrm{H} 2$ : There is a relationship between habit and social media capital affinity.

H3: There is a relationship between perceived ease of use and social media capital affinity.

H4: There is a relationship between social capital affinity and attitudes towards SNS advertisement.

H5: There is a relationship between perceived ease of use and attitudes towards SNS advertisement. 
H6: There is a relationship between habit and attitudes towards SNS advertisement.

\section{Research methodology}

The study adopted the positivist research philosophy and utilised a descriptive research design. Given the hypotheses presented, correlations were used to test associations between variables as argued by Kyeyune (2010). In doing all this, a survey was utilised to collect data from the participating students. Concerning the target population, a sample of students studying at a rural campus in the Eastern Cape Province of South Africa. The study utilised a convenience sampling approach, yielding a total of 289 usable questionnaires from the 350 that were distributed. This yielded a response rate of $82 \%$. The measuring instrument was consisted of scales used in previous studies as shown in table 1 . The questionnaire consisted of three main sections. First, a section soliciting biographical information from the respondents. The second section consisted of the independent variables and these included: a) habit, b) social media capital affinity and finally, c) perceived ease of use. Finally, the dependent variable, attitudes towards social networking sites advertisement. The instrument and its scales were subjected to tests of reliability and validity through the Cronbach Alpha Coefficient test. The outcome of these tests are reported in table 1 . All the scales yielded ratings above 0.70 and this is above the required recommended threshold (Nunnally, 1978).

Respondents who participated in the research were furnished with enough information to provide a truly voluntary and informed consent: the purpose of the study, significance and time expected to take to participate. Furthermore confidentiality and anonymity of the respondents were guaranteed by making sure they were not asked to share their names or identities. Permission to collect data was granted by the Research Ethics Committee of the University of Fort Hare were the data was collected (reference number: MC/2018/050).

\begin{tabular}{|c|c|c|c|}
\hline Scale & $\begin{array}{l}\text { Cronbach } \\
\text { Alpha } \\
\text { Coefficient }\end{array}$ & Example Item & Source \\
\hline Habit & 0.712 & $\begin{array}{l}\text { "Using social media has } \\
\text { become natural to me." }\end{array}$ & $\begin{array}{l}\text { (Shava \& } \\
\text { Chinyamurindi, } \\
2018)^{1}\end{array}$ \\
\hline Perceived Ease of Use & 0.743 & $\begin{array}{l}\text { "I find it easy to get the } \\
\text { social networking site to } \\
\text { do what I want it to do." }\end{array}$ & (Davis, 1989) \\
\hline $\begin{array}{lll}\text { Social Media } & \text { Capital } \\
\text { Affinity } & & \\
\end{array}$ & 0.823 & $\begin{array}{l}\text { "Being with people } \\
\text { visiting } \\
\text { networking sites makes } \\
\text { me want to follow up on } \\
\text { things." }\end{array}$ & (Gerlich, 2010) \\
\hline $\begin{array}{lr}\text { Attitude Toward } & \text { Social } \\
\text { Networking } & \text { Sites } \\
\text { Advertisement } & \\
\end{array}$ & 0.778 & $\begin{array}{lr}\text { "Social } & \text { Networking } \\
\text { Sites } & \text { advertisements } \\
\text { appeal to me." }\end{array}$ & $\begin{array}{l}\text { (Yaakop, } \\
\text { Anuar \& Omar, } \\
\text { 2013). }\end{array}$ \\
\hline
\end{tabular}

Table 1: Summary of Instrument Used 
The data was analysed using descriptive statistics (frequencies and percentages) and Pearson correlation. The data analysis was managed by using Statistical Package for Social Science research (SPSS) version 23. The results are presented in the next section.

\section{Results}

The first set of descriptive analysis that was conducted was by: a) gender, b) ethnic group and finally, c) home language. The results of this are presented in table 2.

\begin{tabular}{llrr}
\hline Variable & Category & Frequency & \% \\
\hline \multirow{3}{*}{ Gender } & Male & 133 & 46.0 \\
& Female & 156 & 54.0 \\
Ethnic group & Black (African) & 236 & 81.7 \\
& Coloured & 26 & 9.0 \\
& White & 10 & 3.5 \\
& Indian & 5 & 1.7 \\
Home language & Other & 12 & 4.2 \\
& & & \\
& Zulu & 39 & 13.5 \\
& English & 26 & 9.0 \\
& Afrikaans & 22 & 7.6 \\
& Xhosa & 202 & 69.9 \\
\hline
\end{tabular}

Table 2: Demographic Variables (By Gender, Ethnic Group \& Home language)

Table 2 shows that there were more females (54\%) respondents than males (46\%) in the sample group. The majority of them were dominated by Black (African) with $81.7 \%$ followed by Coloured population group at $9 \%$, Indians at $1.7 \%$, then Whites at 3.5\% and lastly other at $4.2 \%$. Table 2 further shows that the sample group 13.5\% were speaking isiZulu, 9.0\% English, 7.6\% Afrikaans and 69.9\% spoke IsiXhosa.

Table 3 shows Demographic variables (by Age, higher education and internet usage frequency). 


\begin{tabular}{llll}
\hline Variable & Category & Frequency & \% \\
\hline \multirow{3}{*}{ Age } & Below 20years & 82 & 28.4 \\
& $20-30$ & 167 & 57.8 \\
& $31-40$ & 33 & 11.4 \\
& $41-50$ & 7 & 2.4 \\
Highest level of education & Matric & 194 & 67.1 \\
& Certificate & 16 & 5.5 \\
& Diploma/Degree & 18 & 6.2 \\
& PostGrad & 61 & 21.1 \\
& & & \\
Internet usage frequency & Never & 7 & 2.4 \\
& Daily & 255 & 88.2 \\
& Weekly & 14 & 4.8 \\
& Fortnightly & 5 & 1.7 \\
& Monthly & 8 & 2.8 \\
\hline
\end{tabular}

Table 3: Demographic Variables (By Age, Highest Level of Education \& Internet Usage)

According to table 3 the sample of 289 respondents in a descriptive analysis by age, higher education and internet usage frequency showed that, about $57 \%$ of respondents between the age of 20-30 years, followed by $28.4 \%$ below 20years, $11.4 \%$ between $31-40$ years and $2.4 \%$ between $41-50$ years. The highest level of education description showed that $67 \%$ with matric, $21 \%$ postgraduates, $6.2 \%$ with diplomas and 5.5 certificate. The last variable showing internet usage frequency with $88 \%$ daily, $4.8 \%$ weekly, $2.8 \%$ monthly, $2.4 \%$ never and $1.7 \%$ fortnightly

According to table 4 the sample of 289 respondents in a descriptive analysis by age, higher education and internet usage frequency showed that, about $57 \%$ of respondents between the age of 20-30 years, followed by $28.4 \%$ below 20years, $11.4 \%$ between $31-40$ years and $2.4 \%$ between $41-50$ years. The highest level of education description showed that $67 \%$ with matric, $21 \%$ postgraduates, $6.2 \%$ with diplomas and 5.5 certificate. The last variable showing internet usage frequency with $88 \%$ daily, $4.8 \%$ weekly, $2.8 \%$ monthly, $2.4 \%$ never and $1.7 \%$ fortnightly 


\begin{tabular}{llcr}
\hline Variable & Category & Frequency & \% \\
\hline Do you own a personal computer & Yes & 288 & 78.9 \\
& No & 59 & 20.4 \\
& Unknown & 2 & 0.7 \\
& value & & \\
& & & \\
Computer knowledge & Great & 89 & 30.8 \\
& Good & 105 & 36.3 \\
& Average & 83 & 28.7 \\
& Not so good & 12 & 4.2 \\
Time you most use the internet & Morning & 28 & 9.7 \\
& Afternoon & 77 & 26.6 \\
& Evening & 113 & 39.1 \\
& Late at night & 70 & 24.2 \\
& Unknown & 1 & 0.3 \\
& value & & \\
Time you most use social networking sites & Morning & 18 & 6.2 \\
& Afternoon & 45 & 15.6 \\
& Evening & 131 & 45.3 \\
& Late at night & 94 & 32.5
\end{tabular}

Table 4: Demographic Variables (Computer Ownership, Computer Knowledge \& Internet Use)

The next set of tests concerned Pearson Correlation tests and are reported in table 5

\begin{tabular}{|c|c|c|c|c|c|}
\hline Constructs & Description & $\begin{array}{l}\text { Perceived } \\
\text { Ease of } \\
\text { Use }\end{array}$ & Habit & $\begin{array}{c}\text { Social } \\
\text { Media } \\
\text { Capital } \\
\text { Affinity }\end{array}$ & $\begin{array}{c}\text { Attitudes } \\
\text { Towards SNS } \\
\text { Advertisement }\end{array}$ \\
\hline $\begin{array}{l}\text { Perceived Ease } \\
\text { of Use }\end{array}$ & $\begin{array}{l}\text { Pearson } \\
\text { Correlation }\end{array}$ & 1 & $\begin{array}{ll} & 0.226 * \\
*\end{array}$ & & \\
\hline Habit & $\begin{array}{l}\text { Pearson } \\
\text { Correlation }\end{array}$ & & 1 & 0.094 & \\
\hline $\begin{array}{lr}\text { Social Media } \\
\text { Capital Affinity }\end{array}$ & $\begin{array}{l}\text { Pearson } \\
\text { Correlation }\end{array}$ & 0.065 & & 1 & $0.510 * *$ \\
\hline \multirow[t]{3}{*}{$\begin{array}{l}\text { Attitudes } \\
\text { Towards SNS } \\
\text { Advertisement } \\
\end{array}$} & $\begin{array}{l}\text { Pearson } \\
\text { Correlation }\end{array}$ & $\begin{array}{c}-0.093 \\
\end{array}$ & -0.043 & & 1 \\
\hline & $\begin{array}{ll}* * \text { Sig. } & (2- \\
\text { tailed }) & \end{array}$ & & & & \\
\hline & $\mathrm{N}$ & 289 & 289 & 289 & 289 \\
\hline
\end{tabular}

SNS - Social Networking Sites

Table 5: Correlation Test Results 
Based on table 5 with significance assumed to 2-tailed at 0.01 , the hypotheses tests are reported. Hypothesis 1 sought to test the relationship between perceived ease of use and habit. The results show that there is a relationship between the two variables $\left(0.226^{* *}\right)$, resulting in hypothesis 1 being supported. Concerning hypothesis 2, testing the relationship between habit and social media capital affinity, the results in table 5 show that there is no significant relationship between the variables (0.094), as a result hypothesis 2 is not supported. With regard to hypothesis 3 testing the relationship between social media capital affinity and perceived ease of use, the results show no significance between the variables (0.065). As a result of this hypothesis 3 is not supported. Hypothesis 4 sought to test the relationship between social media capital affinity and attitudes towards social networking advertising, where significance is 2-tailed at 0.01 level and the results show that there is a relationship at $0.510^{* *}$ between the two variables therefore based on the testing hypothesis 4 is supported. With regard to hypothesis 5 , the test was on the relationship between attitude towards social networking advertising and perceived ease of use, where the results show that there is no significance $(-0.093)$. Based on this, hypothesis 5 is not supported. Finally, concerning hypothesis 6 , testing the relationship between attitude towards social networking advertising and habit, the results show that there is no significant relationship between the two and the value of -0.043 was found, which means that the hypothesis is not supported.

\section{Discussion}

The objective of this study was to determine the role of perceived ease of use, habit and social media capital affinity on the attitudes towards social network advertising amongst students at rural campus in South Africa. Concerning, hypothesis 1, a relationship was found to exist perceived ease of use and habit. This is a finding supported by previous research (Borzillo et al., 2011). The logic here appears to be the more an individual findings it easy to use a social media platform it is likely lead into some habitual tendencies. In essence, the positive experience manifest in ease of use lead not only to favourable experiences but positive ratings towards technology use (Caplan, 2002). This despite the propensity of habitual usage likely to lead to addiction of the increased risk of personal and social problems (Lin \& Ma, 2018). Conversely, no relationship was found to exist between habit and social media capital affinity. This despite previous studies showing the existence of a relationship between these variables (Johnson et al., 2013). In other studies, the intensity of using social networking sites existed as a strong predictor to social capital affinity (Barker et al., 2013; Ellison et al., 2014). The major issue and a possible shortcoming of this work would be the lack of delineation of which social networking sites used within our sample. In previous studies (Ellinson et al., 2014) this was done with reference to Facebook as a social networking site. Based on the research some recommendations can be made:

- Theoretically, the study shows support to the relationship between behaviour and attitude (Ajzen \& Fishbein, 1981).

- The findings may have resonance with those tasked with marketing towards the youth market, especially concerning those factors that influence how attitudes towards social networking advertising can be enhanced.

- The findings also heighten focus on developing those social media capital competencies that can assist in informing social networking attitudes.

All research studies have limitations. Concerning this study, the study focused only on three constructs and their influence on attitude towards social networking advertising. Previous research has 
demonstrated that several factors may influence behaviours such as attitude towards social networking advertising. The acknowledgement here could be that other factors could influence attitude towards social networking advertising. Second, the sample consisted of students conveniently selected. Caution should be exercised especially when generalising to other population groups. Thirdly, concerns exist around the framing of some of the constructs in the study. For instance, social media capital affinity, this is a scale developed in Western countries whose relevance may be questioned in developing countries like South Africa. Based on these limitations, some recommendations can be made for future research. First, future could explore the issue that have received focus in this study qualitatively. This can help understand some of the ensuing complexity that accompanies the issues that have received focus in this study. Second, there may be need to be expansive not only in terms of the sample but also the constructs under study. Finally, there may be a need to track the issues explored within the study longitudinally and track any change over a time period. This given the fluid nature of technology usage and advancement with time, a longitudinal measurement is warranted for.

\section{ACKNOWLEDGEMENTS}

The authors acknowledge the support of the Govan Mbeki Research Development Centre and the Research Niche Area within the Faculty of Management and Commerce at the University of Fort Hare.

\section{References}

Adler, P., \& Kwon, S. (2002). Social capital: Prospects for a new concept. Academy of Management Review, 27(1), 17-40.

Ajzen, I. (1991). The theory of planned behavior. Organizational Behavior and Human Decision Processes, 50, 179-211.

Ajzen, I., \& Fishbein, M. (1980). Understanding attitudes and predicting social behavior. Englewood Cliffs, NJ: Prentice-Hall.

Anstead, N., \& O’Loughlin, B. (2015). Social media analysis and public opinion: The 2010 UK general election. Journal of Computer Mediated Communication, 20, 204-220.

Barker, V, Dozier, D. M. Schmitz Weiss, A., \& Borden, D. L. (2013, August). Harnessing Peer Potency: Predicting Positive Outcomes from Social Capital Affinity and Online Engagement With Participatory Websites. Paper presented at the meeting of the Association for Education in Journalism and Mass Communication, Washington, DC.

Borzillo, S., Aznar, S., \& Schmitt, A. (2011). A journey through communities of practice: How and why members move from the periphery to the core. European Management Journal, 29(1), 25-42.

Brush, A. J., Wang, X., Turner, T.C. \& Smith, M.A. (2005). Assessing differential usage of usenet social accounting meta-data. In Proceedings of the SIGCHI Conference on Human Factors in Computing Systems. 889-898.

Caplan, S. E. (2002). Problematic Internet Use and Psychosocial Well-Being: Development of a Theory-Based Cognitive-Behavioral Measurement Instrument. Computers in Human Behavior, 18, 553-575.

Chen, Q., \& Wells, W. D. (2000). A new look at traditional measures: Attitude toward the site. Proceedings of the 2000 Conference of the American Academy of Advertising, 231.

Chinyamurindi, W.T. \& Louw, G. (2010). Gender Differences In Technology Acceptance in Selected South African Companies: Implications For Electronic Learning. South African Journal of Human Resources, 8(1), 1-7.

Coleman, J. S. (1988). Social capital in the creation of human capital. American Journal of Sociology, 94, 95 - 120. 
Davis, F.D. (1989). Perceived usefulness, Perceived Ease of Use and User Acceptance of Information Technology. MIS Quarterly, 13(3), 319-340.

Ellison, N.B., Steinfield, C. \& Lampe, C. (2007). The Benefits of Facebook "Friends:" Social Capital and College Students' Use of Online Social Network Sites. Journal of Computer-Mediated Communication, 4(12), 1143-1168.

Gerlich, R.N. (2010). The Social Media Afinity Scale: Implications For Education. Contemporary Issues in Education Research, 3(11), 35-42.

Hansen, T., Jensen, J., \& Solgaard, H. (2004). Predicting Online Grocery Buying Intention: A Comparison of the Theory of Reasoned Action and the Theory of Planned Behavior. International Journal of Information Management, 24(6), 539-550.

Haythornthwaite, C. (2005). Social networks and Internet connectivity effects. Information, Communication, \& Society, 8(2), 125-147.

Hyde, M. \& White, K. (2009). To be a donor or not to be? Applying an extended theory of planned behavior to predict posthumous organ donation intentions. Journal of Applied Social Psychology, 39, 880-900.

Johnston, K., Tanner, M., Lalla, N., \& Kawalski, D. (2013). Social capital: The benefit of Facebook 'friends'. Behaviour \& Information Technology, 32(1), 24-36.

Kyeyune, A.P., (2010). The interpretation and use of mixed methods research within programme evaluation practice. Master's thesis, The University of Stellenbosch, Stellenbosch, South Africa.

Lau, W. F. (2017). Effects of social media usage and social media multitasking on the academic performance of university students: Computers in Human Behaviour, 68, 286-291.

Lau, H.T. \& Lee, R. (2018). Ethnic media advertising effectiveness, influence and

Implications. Australian Marketing Journal, 26(3), 1-5.

Lin, Y. (2008). Media dependency theory. Sage: London.

Liu, C. \& Ma, J. (2018). Development and validation of the Chinese social media addiction scale. Personality and Individual Differences, 134, 55-59.

Ma, W.W.K. \& Chan, A. (2014). Knowledge sharing and social media: Altruism, perceived online attachment motivation, and perceived online relationship commitment. Journal of Computers in Human Behavior, 39, 51-58.

Meier, A., Reinecke, L. \& Meltzer, C.E. (2016). 'Facebocration? Predictors of using Facebook for procrastination and its effects on students well-being. Computers in Human Behaviour, 110, 16-34.

Nunnally, J.C. (1978). Psychometric theory. (2nd Edition). McGraw-Hill, New York.

Rodgers, S., \& Sheldon, K. M. (2000). Predicting banner effects by knowing web motives. Working paper, University of Minnesota, School of Journalism and Mass Communication.

Shava, H. \& Chinyamurindi, W.T. (2018). Determinants of social media usage among a sample of rural South African youth. South African Journal of Information Management, 20(1), 1-8.

Steinfield, C., Ellison, N. B., \& Lampe, C. (2008). Social capital, self - esteem, and use of online social network sites: A longitudinal analysis. Journal of Applied Developmental Psychology, 29 (6), $434-445$.

Thurairaj, S., Hoon, E.P., Roy, S.S., Fong, P.W., Tunku, U. \& Rahman, A. (2015). Reflections of students' language usage in social networking sites: Making or marring academic English. Universiti Tunku Abdul Rahman, 13(4), 302-316.

Woo, S. \& Lee, J. (2017). Telematics and informatics a comparative study of Kakao Story and Facebook: Focusing on use patterns and use motives. Telematics and Informatics, 34(1), 220-229.

van Rhyne, Z., Chinyamurindi,W.T. \& Cilliers, L. (2019). Social Network Addiction and Advertising on Social Networks: A Case Study of Rural Students in South Africa. South African Journal of Information Management, 21(1), 1-7.

Yaakop, A., Anuar, M.M. \& Omar, K. (2013). Like It or Not: Issue of Credibility in Facebook Advertising. Asian Social Science, 9(3), 154-163. 
Yoo, Y., Henfridsson O. \& Lyytinen, K. (2010). The New Organizing Logic of Digital Innovation: An Agenda for Information System Research. Information Systems Research 21(4), 724-735. 